\title{
GEOLOGY \& GEOPHYSICS FOR THE EXPLORATION OF MARINE MINERAL RESOURCES
}

\section{INTRODUCTION}

\author{
Special Editors: Sidney L. M. Mello \& Jorge J. C. Palma
}

The oceans cover about $71 \%$ of Earth's surface of the and represent an important system for all mankind. The oceans are an extensive source of living and non-living resources. They are responsible for the positive balance of oxygen in the atmosphere due to by means of the planctonic metabolism and also as well as for our climate as result of the water mass temperature and distribution.

Twelve of the largest urban areas in the world are located within $160 \mathrm{~km}$ from the coast line, demonstrating our increasing relation with the oceans under different aspects, including fishery, transports, leisure, security and mineral exploitation. Particularly, Brazil has about $8,000 \mathrm{~km}$ long littoral, which represents a privileged position in terms of sustainable exploitation of marine resources.

The salt in the seawater is naturally a mineral resource and source of important chemical elements, such as $\mathrm{Cl}, \mathrm{Na}, \mathrm{Mg}, \mathrm{K}, \mathrm{Br}, \mathrm{Sr}$ and B. But, only few elements are commercially extracted from the seawater in large scale such as sodium $(\mathrm{Na})$, chlorine $(\mathrm{Cl})$, magnesium $(\mathrm{Mg})$ and brome $(\mathrm{Br})$.

Although the seawater is rich in elements with economic value, at large extend the mineral resources found in the oceans are related to specific geological environments, which reveals the interaction between the seawater with sediment deposition, biological activity and magmatism. This shows that different processes contribute to enrich the mineral deposits and ore formation, such as precipitation, sedimentation, biological metabolism, diagenesis and volcanic activity.

Despite of three decades of ocean research, the economic potential of the marine mineral resources is lesser than that expected in the 70 's. The oil exploration is still very important as major source of energy, but only few other marine deposits are economically mined: marine placers, gravel and sand, shells, evaporites and fosforites. However, marine deposits may well represent important resource in a medium and long term, depending on the changes in the international scenario. Therefore, such deposits, which may represent a strategic reserve, should be thoroughly investigated.

The Brazilian government through the Interministerial Commission for the Marine Resources (CIRM) is aware of this issue and established in 1997 the REMPLAC Program to evaluate the potential of marine mineral deposits on the Brazilian extended "legal" continental shelf (Plataforma Continental Juridica Brasileira). Since then, this program has supported workshops and research on this issue.

With support of the REMPLAC Program the Departamento de Geologia-LAGEMAR/ Universidade Federal Fluminense hosted between the $21^{\text {st }}$ and $31^{\text {st }}$ of August 2000 a Seminar on Marine Mineral Resources. Particularly, the Secretariat of the Interministerial Commission for the Marine Resources (SECIRM), the Brazilian Geological and Geophysical Program (PGGM) and the Brazilian Geological Survey (CPRM) provided means for the success of that event. Additional support was provided by the Brazilian Geophysical Society (SBGf), the Rio de Janeiro State Research Foundation of Research the Rio de Janeiro State (FAPERJ) and the Rio de Janeiro State Department of Mineral Resources of the Rio de Janeiro State (DRM/RJ).

As a first result of the seminar we elaborated a $\mathrm{CD}-\mathrm{ROM}$ with a synthesis of the oral presentations (Departamento de Geologia-LAGEMAR, Llimited edition of the Departamento de Geologia$L A G E M A R$ ). In this special issue of the Brazilian Journal of Geophysics, we present the complete articles resulting of evolved from those presentations. Peter Rona opens this edition demarcating the importance of the marine mineral resources in the $21^{\text {st }}$ 
century. A total of 14 articles deal with exploration methods and techniques, marine mineral deposits and mining and environmental impacts and legal aspects. Contribute with articles Alberto Figueiredo, Abílio Gomes, Arthur Aiiyres Neto, Ben Clennell, Cleverson Silva, Gilberto Dias, Isa Brehme, Ivo Pessanha, Jorge Palma, Kaiser de Souza, Marcelo Sperle Dias, Sandra Quental and Sidney Mello. Their articles were submitted to the journal in August 2000 and accepted for publication in August/September 2001. Just in time we add to this special issue two invited papers. Bramley Murton shows a global review of non-living resources on the extended continental shelf, while Edson Milani, José Augusto Brandão, Pedro Zalán and Luiz Gamboa show the development of the oil exploration on the Brazilian Continental Margin. Other colleagues collaborated in different ways along this edition: Adalberto Silva, Alexandre Tagore de Albuquerque, Carlos Schobbenhaus, Davi Santiago de Macedo, Egydio Chianello, Emmanuel T. de Queiroz, Fernando Barriga, Flávio Luiz Giacomazzi,
George Satander Freire, Geraldo Cunha, Hugo Camerini, Ícaro Vitorello, José A. Baptista Neto, Jurandyr Schmidt, Marco Aurélio Latgé, Marcus Aguiar Gorini, Norberto Olmiro H. Filho, Rubens Rulli Costa, Sergio Jacques and Susanna E. Sichel.

This special issue is an update on the marine mineral resources, including the deep-sea deposits (polymetallic sulfides and nodules) that have strong strategic value because they occur mainly in international waters and sooner or later Brazil will have to deal withestablish its policy on this matter. This edition also covers a gap in Brazilian references on marine mineral resources, mainly with most of the papers in Portuguese language.

Here we display a review on the state of the art about the geology and geophysics for the exploration of marine mineral resources over different geological settings, characterizing also the environmental studies associated with mining activities and legal aspects on the exploration of the oceans.

\section{UFF - Fluminense Federal University}

\section{LAGEMAR - Laboratory of Marine Geology}

Offers graduate courses in Geology and Marine Geophysics with a staff of 11 $\mathrm{PhD}$. LAGEMAR is involved in important national and international projects of oceanography and aerial geophysical surveys making use of advanced scientific research techniques in Marine Geology and Marine Geophysics.

Visit http://www.igeo.uff.br/lagemar; - Contact lagemar@igeo.uff.br 